\title{
Antioxidant, anti-inflammatory and anticoagulant activities of three Thymus species grown in southeastern Morocco
}

\author{
Abdelbassat Hmidani ${ }^{1,2}$, Eimad Dine Tariq Bouhlali ${ }^{2,3^{*}}$ (D, Tarik Khouya ${ }^{2}$, Mhamed Ramchoun ${ }^{2,4}$, \\ Younes Filali-Zegzouti ${ }^{1}$, Chakib Alem² ${ }^{2}$ and Mohamed Benlyas ${ }^{1}$
}

\begin{abstract}
Background: Thyme has been used for centuries in southeastern Morocco to treat a wide range of diseases such as inflammation disorders. The aim of the current study is to examine and to compare in vitro the anti-inflammatory, antioxidant, and anticoagulant activities of three thyme species grown in southeastern Morocco.

Results: Data showed that all studied species possess an important antioxidant activity: Thymus atlanticus $\left(\mathrm{IC}_{50}=\right.$ $16.59 \mu \mathrm{g} / \mathrm{mL})$, Thymus zygis $\left(\mathrm{IC}_{50}=15.43 \mu \mathrm{g} / \mathrm{mL}\right)$, and Thymus satureioides $\left(\mathrm{I}_{50}=14.65 \mu \mathrm{g} / \mathrm{mL}\right)$. Concerning the antiinflammatory activity, the highest effect was depicted in Thymus atlanticus followed by Thymus zygis and Thymus satureioides. With regard to the anticoagulant activity, the aqueous extract of these species prolongs activated partial thromboplastin time, prothrombin time, and thrombin time significantly $(p<0.05)$ in a dose-dependent manner.

Conclusion: Our results provide evidence that thymus extract exhibits marked antioxidant, anticoagulant, and antiinflammatory effects, thus justifying the popular uses of these plants to treat some inflammatory and cardiovascular illnesses.
\end{abstract}

Keywords: Antioxidant, Anti-inflammatory, Anticoagulant, Thymus species, Thrombin time

\section{Background}

Inflammation is defined as a complex biological response of vascular tissues against aggressive agents such as pathogens, irritants, and damaged cells [1]. Inflammation and coagulation are two main host-defense systems that interact with each other [2]. Increasing evidence points to an extensive cross-talk between these two systems; indeed, inflammation activates coagulation and coagulation modulates the inflammatory activity in many ways [2]. Inflammation and coagulation are implicated in many cardiovascular diseases such as thrombosis and atherosclerosis [3]. Therefore, any agent with anti-inflammatory and anticoagulant activities might potentially prevent the rate of several diseases, mainly cardiovascular ones. Steroidal and nonsteroidal antiinflammatory drugs used to remedy the inflammatory-

\footnotetext{
* Correspondence: bouhlali.eimad@gmail.com

${ }^{2}$ Biochemistry of Natural Product Team, Faculty of Sciences and Techniques Errachidia, Moulay Ismail University, Zitoune, BP 11201 Meknes, Morocco ${ }^{3}$ Regional Center for Agricultural Research, Mly Ali Cherif avenue, P.O 2, Errachidia, Morocco

Full list of author information is available at the end of the article
}

related diseases can cause severe adverse side effects such as gastrointestinal ulceration, perforation, obstruction, bleeding, and cardiovascular and renal failure [4]. Further, anticoagulants have been widely used as a treatment of disseminated intravascular coagulation and thrombosis in various diseases especially in cardiovascular diseases $[5,6]$. However, besides its beneficial effects, they have a variety of undesirable effects [7]. Therefore, there is a need to develop safer and more efficient anti-inflammatory agents from folk medicine, which have regained their popularity in the treatment of several human ailments in the last few decades.

Thyme is a perennial herbaceous plant, which belongs to the Lamiaceae family and native to temperate regions in Europe, North Africa, and Asia. Thyme has been used for centuries not only for culinary dishes (as spice and liqueur flavor agent), but also for a several therapeutic purposes. Traditionally, it is well-known for its use as folk remedy for gastrointestinal and respiratory disorders, cough, menstrual cramps, and bacterial, parasitic, and fungal infections [8]. Thyme is helpful in the treatment of inflammation 
disorders, and it is most frequently used to improve liver functioning and act as an appetite stimulant [9]. Over the last two decades, more and more studies have conducted to evaluate some biological activities of thyme, which showed its antioxidant, antimicrobial, anti-inflammatory, immunomodulatory, and antitumor properties [8]. Moreover, our previous study has shown that Thymus species have significant amounts of phenolic and flavonoid compounds and exhibit strong antioxidant activities [10].

This study aims to investigate and to compare the antioxidant, anti-inflammatory, and anticoagulant effects of three aqueous extracts obtained from three Thymus species grown in southeastern Morocco.

\section{Materials and methods \\ Plant material}

The aerial parts of three thyme species (Thymus zygis, Thymus satureioides, and Thymus atlanticus) were collected in the Errachidia region (southeastern Morocco), during the flowering period (April/June 2016). After the taxonomic identification and authentication of the plants by Dr. Ben Tatou (Botanist at the Scientific Institute, Rabat, Morocco), voucher specimens of $T$. zygis $L, T$. satureioides Cosson (No: RAB 77497), subsp. gracilis (Boiss.) R. Morales (No: RAB 77494), and Thymus cf. atlanticus (Ball) Roussine (No: RAB 77496) were deposited in the herbarium of the Scientific Institute.

Plant material was dried, and then stored in the dark at room temperature $\left(25^{\circ} \mathrm{C}\right)$ before extraction.

\section{Preparation of rich polyphenol extracts}

The air-dried aerial parts ( $30 \mathrm{~g}$ ) were ground and then extracted with double-distilled boiling water $(450 \mathrm{~mL})$ using a Soxhlet extractor for $5 \mathrm{~h}$. The extracts were concentrated to dryness, and the residues were stored at $4{ }^{\circ} \mathrm{C}$.

\section{In vitro antioxidant activity using ABTS assay}

The ABTS antioxidant activity was measured according to the technique described by Bouhlali et al. [11]. The ABTS radical cations (ABTS+) were made following the reaction between the aqueous solution of ABTS (7 mM) and the aqueous solution of potassium persulphate $(2.45 \mathrm{mM})$. The mixture was put in the dark at room temperature for $12-16 \mathrm{~h}$ before use, and then diluted with distilled water to reach an absorbance of $0.700 \pm$ 0.005 at $734 \mathrm{~nm}$. Different concentrations of the sample $(30 \mu \mathrm{L})$ were added to $3 \mathrm{~mL}$ of the ABTS solution; after incubation for $6 \mathrm{~min}$ at room temperature, the absorbance at $734 \mathrm{~nm}$ was taken immediately. The $\mathrm{IC}_{50}$ (concentration providing $50 \%$ inhibition) values were calculated from the plotted graph of scavenging activity against the concentrations of the samples.

\section{In vitro anti-inflammatory activity} Inhibition of albumin denaturation

The inhibition of albumin denaturation was measured using Chandra et al.'s method [12], with slight adjustments. Briefly, $1 \mathrm{~mL}$ of $1 \%$ bovine serum albumin (prepared in phosphate-buffered saline, $\mathrm{pH}$ 6.4) was added to $1 \mathrm{~mL}$ of variable concentrations of plant extract (200$1500 \mu \mathrm{g} / \mathrm{mL}$ ). This mixture was left for $20 \mathrm{~min}$ at room temperature and then heated at $70{ }^{\circ} \mathrm{C}$ for $5 \mathrm{~min}$. The resultant solution was getting cold to room temperature, and their turbidities were read at $660 \mathrm{~nm}$. The same process was recurring using double-distilled water, and the indomethacin was considered as control and standard respectively. The inhibition percentage (IP \%) of protein denaturation was calculated as follows:

Percentage inhibition (IP \%) $=(($ Abs control - Abs sample $) /($ Abs control $) \times 100$, where Abs control is the absorbance without sample and Abs sample represents the absorbance of sample extract/standard.

\section{The membrane stabilization potential}

The membrane stabilizing effect was determined using the method described by Murugan and Parimelazhagan [13]. Sterilized Alsever's solution, prepared by dissolving citric acid $(0.05 \%)$, sodium chloride $(0.42 \%)$, sodium citrate $(0.8 \%)$, and dextrose $(2 \%)$ in distilled water, was mixed with equal volume of blood collected from healthy human volunteers who did not use any NSAIDS for 15 days before blood collection. After centrifugation at $3000 \mathrm{rpm}$ of result, blood solution, the cell pellet was washed with isotonic saline $(9 \mathrm{~g} / \mathrm{L})$ which was used then to prepare a suspension containing $10 \%$ cell pellet. The assay mixture contains $1 \mathrm{~mL}$ of phosphate-buffered saline, $0.5 \mathrm{~mL}$ of blood suspension (10\%), $0.5 \mathrm{~mL}$ of a plant extract with various concentrations of 200 to $1500 \mu \mathrm{g} / \mathrm{mL}$, and $2 \mathrm{ml}$ of hypotonic saline $(3.6 \mathrm{~g} / \mathrm{L})$. After incubation for $30 \mathrm{~min}$ at $37^{\circ} \mathrm{C}$, the mixtures were centrifuged at $3000 \mathrm{rpm}$ and the hemoglobin content of supernatant was estimated by a spectrophotometer at $560 \mathrm{~nm}$. Distilled water was used as the negative control. The positive control was diclofenac sodium at the final concentration ranging between 20 and $1000 \mu \mathrm{g} / \mathrm{mL}$. The percentage of membrane stabilization (\% MS) was determined as follows:

$$
\begin{aligned}
\mathrm{MS} \%= & ((\text { Abs control-Abs sample }) \times 100) \\
& /(\text { Abs control })
\end{aligned}
$$

where Abs control is the absorbance without plant material and Abs sample is the absorbance of plant extract or standard. Again, the $\mathrm{IC}_{50}$ was calculated from a graph defining inhibition against the different concentrations. 


\section{In vitro anticoagulant activity}

In vitro anticoagulant activity was determined by the method described by Athukorala et al. [14] with very little modifications. Briefly, $8 \mathrm{~mL}$ of pooled normal human plasma was prepared from a healthy individual with no history of abnormal bleeding. The peripheral venous blood was collected in polypropylene tubes with $3.8 \%$ sodium citrate $(9: 1)$ and was centrifuged for $15 \mathrm{~min}$ at $2400 \mathrm{~g}$.

All coagulation assays were repeated six times using a coagulometer (Stago start 4, French), and the average of the assays was taken. For activating partial thromboplastin time (APTT) assay, $50 \mu \mathrm{L}$ of citrated normal human plasma was mixed with $25 \mu \mathrm{L}$ of aqueous extract and incubated for $10 \mathrm{~min}$ at $37^{\circ} \mathrm{C}$, then $50 \mu \mathrm{L}$ of APTT reagent was added to the mixture and incubated for $3 \mathrm{~min}$ at $37^{\circ} \mathrm{C}$. Thus, by adding $50 \mu \mathrm{L}$ of $\mathrm{CaCl}_{2}(0.025 \mathrm{~mol} / \mathrm{L})$, clotting was prompted and time was recorded.

In prothrombin time (PT) assay, $50 \mu \mathrm{L}$ of citrated normal human plasma was mixed with $25 \mu \mathrm{L}$ of aqueous extract and incubated for $10 \mathrm{~min}$. Then, $100 \mu \mathrm{L}$ prothrombin time reagent, pre-incubated for $10 \mathrm{~min}$ at $37^{\circ} \mathrm{C}$, was added and clotting time was recorded. For thrombin time (TT) measurement, $100 \mu \mathrm{L}$ of citrated normal human plasma was mixed with $25 \mu \mathrm{L}$ of aqueous extract and incubated for $10 \mathrm{~min}$. Then, clotting time was recorded after adding $50 \mu \mathrm{L}$ of pre-incubated $\mathrm{TT}$ reagent $\left(10 \mathrm{~min}\right.$ at $\left.37^{\circ} \mathrm{C}\right)$ to the mixture.

\section{Statistical analysis}

Statistical analysis was performed using StatView 5.0 software. The experimental results were reported as the average of five repetitions for all the experiments $\pm \mathrm{SE}$ (standard error). Analysis of variance (ANOVA) and post hoc Bonferroni $(p<0.0018)$ tests were used to compare the experimental groups. Pearson's correlation coefficient $(r)$ was used to measure the association between two variables. Differences at $p<0.05$ were considered significant.

\section{Results and discussion}

\section{Evaluation of antioxidant activity}

The antioxidant activity was carried out using ABTS assay, which measures the ability of antioxidant to scavenge the $(\mathrm{ABTS}+\bullet)$ radical generated in aqueous phase. As revealed in Table 1, all samples exhibit a potent antioxidant activity $\left(\mathrm{IC}_{50}=16.59 \mu \mathrm{g} / \mathrm{mL}\right.$ for Thymus atlanticus, $\mathrm{IC}_{50}=$ $15.43 \mu \mathrm{g} / \mathrm{mL}$ for Thymus zygis, and $\mathrm{IC}_{50}=14.65 \mu \mathrm{g} / \mathrm{mL}$ for Thymus satureioides). Significant difference $(p<0.01)$ was observed among the studied Thymus species. These scavenging abilities are very less than that of ascorbic acid used as a reference antioxidant $\left(\mathrm{IC}_{50}=1.96 \mu \mathrm{g} / \mathrm{mL}\right)$.

This finding supports our previous studies, which have mentioned the potent antioxidant activities of aqueous extracts of selected thyme species using DPPH, FRAP assays,
Table 1 Antioxidant activity of studied thymus species based on ABTS assay

\begin{tabular}{lc}
\hline Sample & $I_{50}(\mu \mathrm{g} / \mathrm{mL})$ \\
\hline Thymus atlanticus & $16.59 \pm 0.32$ \\
Thymus zygis & $15.43 \pm 0.44$ \\
Thymus satureioides & $14.65 \pm 0.36$ \\
Ascorbic acid & $1.96 \pm 0.1$ \\
\hline All data expressed as mean values \pm SD $(n=6)$ represented by error bars
\end{tabular}

and inhibition AAPH-induced oxidative hemolysis [15]. These results are lower than those reported by Roby et al. [16] for Thymus vulgaris and Labiad et al. [17] for Thymus satureioides. These strong antioxidant activities might be caused by the high content of phenol compounds and flavonoids, which have been reported to be implicated in free radical scavenging [18].

\section{Anti-inflammatory activity Inhibition of protein denaturation}

Auto-antigens produced during protein denaturation induced type III hypersensitivity reaction, which in turn is associated with illnesses, for instance, rheumatoid arthritis, serum sickness, glomerulonephritis, and systemic lupus erythematosus [19]. Several nonsteroidal anti-inflammatory drugs have been reported to prevent denaturation of proteins in addition to their capability to prevent endogenous prostaglandin production by blocking COX enzyme [20]. Hence, the ability of plant extract to prevent protein denaturation makes it possibly useful for anti-inflammatory remedy development.

The results in Table 2 indicate that all Thymus species inhibited the denaturation of bovine serum albumin in a dose-dependent manner. The potency order was as shown here: Thymus atlanticus $\left(\mathrm{IC}_{50}=122.90 \mu \mathrm{g} / \mathrm{mL}\right)$ exhibits the greatest prevention of protein denaturation, followed by Thymus zygis $\left(\mathrm{IC}_{50}=133.25 \mu \mathrm{g} / \mathrm{mL}\right)$ and Thymus satureioides $\left(\mathrm{IC}_{50}=181.42 \mu \mathrm{g} / \mathrm{mL}\right)$.

These effects are close to that reported for indomethacin $\left(\mathrm{IC}_{50}=86.07 \mu \mathrm{g} / \mathrm{mL}\right)$ which is the standard antiinflammation drug. This result may be due to the high quantity of polyphenols found in these Thymus species, which are found to promote anti-inflammatory activity

Table $\mathbf{2}$ In vitro anti-inflammatory activity aqueous extracts of three Thymus species

\begin{tabular}{lll}
\hline Sample & MSP IC $_{50}(\mu \mathrm{g} / \mathrm{mL})$ & $I P D I C_{50}(\mu \mathrm{g} / \mathrm{mL})$ \\
\hline Thymus atlanticus & $93.28 \pm 1.44$ & $122.9 \pm 1.069$ \\
Thymus zygis & $156.20 \pm 2.25$ & $133.25 \pm 2.20$ \\
Thymus satureioides & $204.41 \pm 2.10$ & $181.42 \pm 2.13$ \\
Indometacin & $97.83 \pm 0.66$ & $86.07 \pm 0.84$ \\
\hline
\end{tabular}

MSP membrane stabilization power, IPD inhibition of protein denaturation 
Table 3 In vitro activated partial thromboplastin time measurements of aqueous extracts in human pooled plasma

\begin{tabular}{llll}
\hline In vitro activated partial thromboplastin time measurement (seconds) & & \\
\hline Concentrations of a sample in the clotting mixture $(\mu \mathrm{g})$ & \multicolumn{1}{l}{ Thymus atlanticus } & Thymus zygis & Thymus satureioides \\
\hline 0.36 & $34.60 \pm 1.09$ & $34.88 \pm 1.05$ & $36.23 \pm 1.39$ \\
0.71 & $34.63 \pm 0.86$ & $37.45 \pm 1.59^{*}$ & $37.82 \pm 1.49^{*}$ \\
1.43 & $35.72 \pm 1.05$ & $38.1 \pm 2.11^{* *}$ & $45.63 \pm 2.44^{* *}$ \\
2.86 & $36.65 \pm 1.18$ & $39.57 \pm 2.11^{* *}$ & $49.20 \pm 3.60^{* *}$ \\
5.7 & $207.10 \pm 6.15^{* * *}$ & $120.00 \pm 7.87^{* * *}$ & $61.95 \pm 1.57^{* * *}$ \\
11.43 & $999 . \pm 0.00^{* * *}$ & $999.00 \pm 0.00^{* * *}$ & $218.55 \pm 1.97^{* * *}$ \\
Negative control & $35.08 \pm 1.53$ & & \\
Unfractionated heparin (0.0007) & $87.63 \pm 3.31^{* * *}$ & &
\end{tabular}

Values are expressed as mean \pm SEM of six measurements. T. zygis, T. atlanticus, and T. satureioides vs negative control

${ }^{*} P<0.05 ;{ }^{* *} P<0.01 ;{ }^{* * *} P<0.001$

[21]. Indeed, Ali et al. [22] showed, using bovine serum albumin (BSA) and bovine 3 -lactoglobulin that the gallic acid, caffeic acid, and coumaric acid improved thermal stability of these proteins. The same results were observed for BSA using ferulic acid [23]. These interactions of polyphenols with proteins have changed the secondary structure of proteins [22].

\section{Membrane stabilizing potential}

Inflammatory response led to a significant secretion of lysosomal enzymes, caused further tissue inflammation, and hence, generates different disorders [24]. Knowing that the erythrocyte membrane is an analogue of the lysosomal membrane and its stabilization implies that the extract can thus stabilize the lysosomal membrane [25]. Hence, the inhibition of erythrocyte lysis induced by hypotonia was employed to examine the antiinflammatory activity of plant material. As figured in Table 2, all extracts displayed a potent inhibition of erythrocyte lysis in a dose-dependent manner. In fact, Thymus atlanticus showed the highest membrane stabilizing effect $\left(\mathrm{IC}_{50}=93.28 \mu \mathrm{g} / \mathrm{mL}\right)$, followed by Thymus zygis $\left(\mathrm{IC}_{50}=156.20 \mu \mathrm{g} / \mathrm{mL}\right)$ and Thymus satureioides $\left(\mathrm{IC}_{50}=204.41 \mu \mathrm{g} / \mathrm{mL}\right)$.
Furthermore, results of the erythrocyte-protective effect found for Thymus atlanticus extract are higher to that of indomethacin $\left(\mathrm{IC}_{50}=97.83 \mu \mathrm{g} / \mathrm{mL}\right)$. These extracts may act by way of cell deformation via their interaction with membrane proteins [26] or other compounds in the erythrocyte membranes, which cause later alteration of the surface charges of the cells.

Flavonoids may interact with the polar head of phospholipids at the water lipid interface, arising membrane rigidity, reduce fluidity and enhance mechanical stability of lipid bilayers [27]. Moreover, Oteiza et al. [28] have suggested that interactions of polyphenols at the surface of bilayers through hydrogen bonding can act to reduce the access of deleterious molecules (i.e., oxidants), therefore protecting the structure and function of membranes. Several reports have mentioned that plant flavonoids and polyphenols have anti-inflammatory characteristics [29].

\section{In vitro anticoagulant activity}

The anticoagulant effect of studied Thymus species was measured using three in vitro assay methods: activated partial thromboplastin time (APTT), prothrombin time (PT), and thrombin time (TT).

Table 4 In vitro prothrombin time measurements of aqueous extract in human pooled plasma

\begin{tabular}{llll}
\hline In vitro prothrombin time (seconds) & & & \\
\hline Concentration of a sample in the clotting mixture $(\mu \mathrm{g})$ & Thymus atlanticus & Thymus zygis & $12.15 \pm-0.24$ \\
\hline 0.35 & $12.37 \pm 0.22$ & $12.22 \pm 0.21$ & $12.13 \pm 0.25$ \\
0.71 & $12.43 \pm 0.27$ & $12.28 \pm 0.23$ & $12.20 \pm 0.14$ \\
1.42 & $12.77 \pm 0.27^{* *}$ & $12.72 \pm 0.23^{*}$ & $12.57 \pm 0.12^{*}$ \\
2.85 & $13.13 \pm 0.15^{* *}$ & $18.30 \pm 0.47^{* * *}$ & $12.62 \pm 0.15^{*}$ \\
5.7 & $22.63 \pm 1.44^{* * *}$ & $46.5 \pm 2.59^{* * *}$ & $34.50 \pm 2.04^{* * *}$ \\
11.43 & $56.82 \pm 1.59^{* * *}$ & &
\end{tabular}

Values are expressed as mean \pm SEM of six measurements. T. zygis, T. atlanticus, and T. satureioides vs negative control

${ }^{*} P<0.05 ;{ }^{* *} P<0.01 ;{ }^{* * *} P<0.001$ 
Table $\mathbf{5}$ In vitro thrombin time measurements of aqueous extracts in human pooled plasma

\begin{tabular}{llll}
\hline Concentrations of a sample in the clotting mixture $(\mu \mathrm{g})$ & Thymus atlanticus & Thymus zygis & Thymus satureioides \\
\hline 0.36 & $17.92 \pm 0.81^{*}$ & $16.65 \pm 0.55$ & $16.13 \pm 0.49$ \\
0.71 & $19.1 \pm 0.61^{* * *}$ & $17.67 \pm 0.22^{* *}$ & $16.28 \pm 0.29$ \\
1.43 & $21.22 \pm 0.72^{* * *}$ & $19.63 \pm 0.68^{* * *}$ & $16.43 \pm 0.66$ \\
2.86 & $23.7 \pm 0.80^{* * *}$ & $24.33 \pm 1.8^{* * *}$ & $19.3 \pm 1.35^{* *}$ \\
5.7 & $29.9 \pm 1.45^{* * *}$ & $26.65 \pm 0.82^{* * *}$ & $24.15 \pm 1.16^{* * *}$ \\
11.43 & $74.46 \pm 1.70^{* * *}$ & $54.21 \pm 3.00^{* * *}$ & $42.16 \pm 1.79^{* * *}$ \\
Negative control & $16.65 \pm 0.64$ & &
\end{tabular}

Values are expressed as mean \pm SEM of six measurements. T. zygis, T. atlanticus, and T. satureioides vs negative control

${ }^{*} P<0.05 ;{ }^{*} P<0.01 ; * * * P<0.001$

APTT assay is used to assess the inhibition of intrinsic factors of blood coagulation pathways such as F XII, XI, $\mathrm{V}$, III IX, and prekallikrein, while PT assay is assessed to examine the inhibition of the extrinsic coagulation pathway, especially factors V, VII, and X [30]. TT assay examines disorders in the final phases of coagulation because it reproduces the blood coagulation that converts fibrinogen into fibrin by the act of thrombin [31].

The results in Tables 3, 4, and 5 show that the aqueous extracts of studied thyme species prolonged significantly the PT, APTT, and TT in a concentrationdependent manner when compared to the negative control. Thymus atlanticus exhibited the highest anticoagulant activity followed by Thymus zygis and Thymus satureioides. In fact, $T$. atlanticus prolonged PT clotting time from 12.37 to $56.82 \mathrm{~s}$, APTT clotting time from 35.08 to $999 \mathrm{~s}$, and TT clotting time from 16.65 to 74.46 $\mathrm{s}$ at the concentration of $11.43 \mu \mathrm{g}$, while $T$. zygis prolonged PT clotting time from 12.37 to $46.5 \mathrm{~s}$, APTT clotting time from 35.08 to $999 \mathrm{~s}$, and TT clotting time from 16.65 to 54.21 and T. satureioides prolonged PT clotting time from 12.37 to $34.50 \mathrm{~s}$, APTT clotting time from 35.08 to $218.55 \mathrm{~s}$, and TT clotting time from 16.65 to $42.16 \mathrm{~s}$ at the same concentration.

According to these results, it is clear that the principal pathways (intrinsic, common, and extrinsic pathways) of the coagulation cascade are significantly affected by thyme species extracts. In this respect, previous works have reported the prolongation effect of polyphenol compound on the coagulation time [32], including rosmarinic acid and caffeic acid, the major phenolic compounds of tested Thyms aqueous extract in this study [15], which mentioned in many works to possess a high effect of inhibition of coagulation time [33, 34]. Hence, these effects could be attributed to their high polyphenol content. Moreover, more studies are necessary to further investigate the active compounds of these plants and the mechanisms involved in action.

\section{Conclusion}

In conclusion, the present findings suggest that the studied Thymus species have important antioxidant, anti-inflammatory, and anticoagulant activities. The differences of these activities among these plants can be attributed to their bioactive compounds. These findings may partly explain the use of those plants in the Moroccan traditional medicine for the treatment of inflammatory and cardiovascular diseases. To illustrate the active component to comprehend their special effects better, more studies are currently in progress.

\section{Abbreviations}

ABTS: Acide 2,2'-azino-bis (3-éthylbenzothiazoline-6-sulphonique); APTT: Activated partial thromboplastin time; BSA: Bovine serum albumin; COX: Cyclooxygenase; PT: Prothrombin time; T.a: Thymus atlanticus; T.s: Thymus satureioides; T.z: Thymus zygis; TT: Thrombin time

\section{Acknowledgements}

The authors would like to thank Pr Khalid Sellam, Dr. Bouchra Bourkhis, and Pr Aissam Bammou for their assistance and valuable guidance.

\section{Authors' contributions}

We declare that this work was done by the authors named in this article: CA, $M B$, and $E D B$ conceived and designed the study. $A H$ and EDB carried out the laboratory work and collected and analyzed the data and writing of the manuscript. TK, MR, and YFZ helped supervise the work and assisted in the data analysis while EDB revised and corrected the manuscript. All authors read and approved the final manuscript.

\section{Funding}

The authors have no funding to report.

Availability of data and materials

The data used to support the findings of this study are available from the corresponding author upon request.

\section{Ethics approval and consent to participate}

This article does not contain any studies involving animals performed by any of the authors. This research involving human material (blood) has been performed in accordance with the 1964 Helsinki Declaration and its later amendments or comparable ethical standards, and this study protocol was approved by the Ethics Committee for Biomedical Research, Faculty of Medicine and Pharmacy of Rabat (FMPR), Morocco, under reference number FMPR-19/2016. 


\section{Consent for publication}

For this manuscript, written informed consent for publication has been obtained from the participants.

\section{Competing interests}

The authors declare that they have no competing interests.

\section{Author details}

${ }^{1}$ Biology, Environment and Health Team, Faculty of Sciences and Techniques Errachidia, Moulay Ismail University, Zitoune, BP 11201 Meknes, Morocco. ${ }^{2}$ Biochemistry of Natural Product Team, Faculty of Sciences and Techniques Errachidia, Moulay Ismail University, Zitoune, BP 11201 Meknes, Morocco. ${ }^{3}$ Regional Center for Agricultural Research, Mly Ali Cherif avenue, P.O 2, Errachidia, Morocco. ${ }^{4}$ Laboratory of Biotechnology and Sustainable Development of Natural Resources, Polydisciplinary Faculty, 23000 Beni Mellal, Morocco.

\section{Received: 2 July 2019 Accepted: 9 September 2019}

\section{Published online: 18 September 2019}

\section{References}

1. Sarkhel S (2016) Evaluation of the anti-inflammatory activities of Quillaja saponaria Mol. saponin extract in mice. Toxicol Rep 3:1-3. https://doi.org/10. 1016/j.toxrep.2015.11.006

2. Petäjä J (2011) Inflammation and coagulation. An overview. Thromb Res 127:34-37. https://doi.org/10.1016/S0049-3848(10)70153-5

3. Strukova S (2006) Blood coagulation-dependent inflammation. Coagulationdependent inflammation and inflammation-dependent thrombosis. Front Biosci 11(1):59-80

4. Shaikh RU, Pund MM, Gacche RN (2016) Evaluation of anti-inflammatory activity of selected medicinal plants used in Indian traditional medication system in vitro as well as in vivo. J Tradit Complement Med 6(4):355-361. https://doi.org/10.1016/j.jtcme.2015.07.001

5. Ito N, Fukushima S, Tsuda H (1985) Carcinogenicity and modification of the carcinogenic response by $\mathrm{BHA}, \mathrm{BHT}$, and other antioxidants. Crit Rev Toxico 15(2):109-150. https://doi.org/10.3109/10408448509029322

6. Ahrens I, Lip GY, Peter K (2010) New oral anticoagulant drugs in cardiovascular disease. Thromb Haemost 104(01):49-60. https://doi.org/10. 1160/TH09-05-0327

7. Kuhn M, Campillos M, Letunic I, Jensen LJ, Bork P (2010) A side effect resource to capture phenotypic effects of drugs. Mol Syst Biol 6(1):343. https://doi.org/10.1038/msb.2009.98

8. Hosseinzadeh S, Kukhdan AJ, Hosseini A, Armand R (2015) The application of Thymus vulgaris in traditional and modern medicine: a review. Global J Pharm 9:260-266. https://doi.org/10.5829/idosi.gjp.2015.9.3.94246

9. Jarić S, Mitrović M, Pavlović P (2015) Review of ethnobotanical, phytochemical, and pharmacological study of Thymus serpyllum L. Evid Based Complement Alternat Med. https://doi.org/10.1155/2015/101978

10. Khouya T, Ramchoun M, Hmidani A, Amrani S, Harnafi H, Benlyas M, FilaliZegzouti Y, Alem C (2015) Anti-inflammatory, anticoagulant and antioxidant effects of aqueous extracts from Moroccan thyme varieties. Asian Pac J Trop Med 5(8):636-644. https://doi.org/10.1016/j.apjtb.2015.05.011

11. Bouhlali EDT, Ramchoun M, Alem C, Ghafoor K, Ennassir J, Zegzouti YF (2017) Functional composition and antioxidant activities of eight Moroccan date frui varieties (Phoenix dactylifera L.). J Saudi Soc Agric Sci 16(3):257-264. https://doi.org/10.1016/j.jssas.2015.08.005

12. Chandra S, Chatterjee P, Dey P, Bhattacharya S (2012) Evaluation of in vitro antiinflammatory activity of coffee against the denaturation of protein. Asian Pac J Trop Biomed 2(1):178-180. https://doi.org/10.1016/S2221-1691(12)60154-3

13. Murugan R, Parimelazhagan $T$ (2014) Comparative evaluation of different extraction methods for antioxidant and anti-inflammatory properties from Osbeckia parvifolia Arn.-an in vitro approach. J King Saud Univ Sci 26(4): 267-275. https://doi.org/10.1016/j.jksus.2013.09.006

14. Athukorala Y, Jung WK, Vasanthan T, Jeon YJ (2006) An anticoagulative polysaccharide from an enzymatic hydrolysate of Ecklonia cava. Carbohydr Polym 66(2):184-191. https://doi.org/10.1016/j.carbpol.2006.03.002

15. Ramchoun M, Harnafi H, Alem C, Benlyas M, Elrhaffari L, Amrani S (2009) Study on antioxidant and hypolipidemic effects of polyphenol-rich extracts from Thymus vulgaris and Lavendula multifida. Phcog Res 1(3):106-118

16. Roby MHH, Sarhan MA, Selim KAH, Khalel KI (2013) Evaluation of antioxidant activity, total phenols and phenolic compounds in thyme
(Thymus vulgaris L.), sage (Salvia officinalis L.), and marjoram (Origanum majorana L.) extracts. Ind Crop Prod 43:827-831. https://doi.org/10.1016/ j.indcrop.2012.08.029

17. Labiad MH, Harhar H, Ghanimi A, Tabyaoui M (2017) Phytochemical screening and antioxidant activity of Moroccan Thymus satureioïdes extracts. Mat Env Sci 8(6):2132-2139

18. Junejo JA, Gogoi G, Islam J, Rudrapal M, Mondal P, Hazarika H, Zaman K (2018) Exploration of antioxidant, antidiabetic and hepatoprotective activity of Diplazium esculentum-a wild edible plant from North Eastern India. Future J Pharm Sci 4(1):93-101. https://doi.org/10.1016/j.fjps.2017.10.005

19. Williams LAD, O'Connar A, Latore L, Dennis O, Ringer S, Whittaker JA, Kraus W (2008) The in vitro anti-denaturation effects induced by natural products and non-steroidal compounds in heat treated (immunogenic) bovine serum albumin is proposed as a screening assay for the detection of antiinflammatory compounds, without the use of animals, in the early stages of the drug discovery process. West Indian Med J 57(4):327-331. https://doi. org/10.1215/9780822388630-010

20. Paul Al (1996) Analgesic-antipyretics and anti-inflammatory agents and drugs employed in the treatment of gout. In: The pharmacological basis of therapeutics, pp 617-657

21. Bouhlali EDT, El Hilaly J, Ennassir J, Benlyas M, Alem C, Amarouch MY, FilaliZegzouti Y (2018) Anti-inflammatory properties and phenolic profile of six Moroccan date fruit (Phoenix dactylifera L.) varieties. J King Saud Univ Sci 30(4):519-526. https://doi.org/10.1016/j.jksus.2017.08.011

22. Ali H, Alli I, Ismail A, Kermasha S (2012) Method development to identify protein-phenolic interactions. Eurasian J Anal Chem 7(3):123-133

23. Ojha H, Mishra K, Hassan Ml, Chaudhury NK (2012) Spectroscopic and isothermal titration calorimetry studies of binding interaction of ferulic acid with bovine serum albumin. Thermochim Acta 548:56-64. https://doi.org/ 10.1016/j.tca.2012.08.016

24. Lima JH, Jacobson L, Goldberg M, Chandran K, Diaz-Griffero F, Lisanti MP, Brojatsch J (2013) Role of lysosome rupture in controlling Nlrp3 signaling and necrotic cell death. Cell Cycle 12(12):1868-1878. https://doi.org/10.4161/cc.24903

25. Anosike CA, Obidoa O, Ezeanyika LU (2012) Membrane stabilization as a mechanism of the anti-inflammatory activity of methanol extract of garden egg (Solanum aethiopicum). DARU J Pharm Sci 20(1):76. https://doi.org/10. 1186/2008-2231-20-76

26. Shinde UA, Phadke AS, Nair AM, Mungantiwar AA, Dikshit VJ, Saraf MN (1999) Membrane stabilizing activity—a possible mechanism of action for the anti-inflammatory activity of Cedrus deodara wood oil. Fitoterapia 70(3):251-257. https://doi.org/10.1016/S0367-326X(99)00030-1

27. Tarahovsky YS, Kim YA, Yagolnik EA, Muzafarov EN (2014) Flavonoidmembrane interactions: involvement of flavonoid-metal complexes in raft signaling. Biochim Biophys Acta 1838(5):1235-1246. https://doi.org/10.1016/ j.bbamem.2014.01.021

28. Oteiza PI, Erlejman AG, Verstraeten SV, Keen CL, Fraga CG (2005) Flavonoidmembrane interactions: a protective role of flavonoids at the membrane surface? Clin Dev Immunol 12(1):19-25. https://doi.org/10.1080/10446670410001722168

29. Bouhlali EDT, Sellam K, Bammou M, Alem C, Filali-Zegzouti Y (2016) In vitro antioxidant and anti-inflammatory properties of selected Moroccan medicinal plants. J Appl Pharm Sci 6(5):156-162. https://doi.org/10.7324/JAPS.2016.60525

30. Kamal AH, Tefferi A, Pruthi RK (2007) How to interpret and pursue an abnormal prothrombin time, activated partial thromboplastin time, and bleeding time in adults. Mayo Clin Proc 82(7):864-873. https://doi.org/10.4065/82.7.864

31. Undas A (2017) Determination of fibrinogen and thrombin time (TT). In: Hemostasis and thrombosis. Humana Press, New York, pp 105-110. https:// doi.org/10.1007/978-1-4939-7196-1_8

32. Luceri C, Giannini L, Lodovici M, Antonucci E, Abbate R, Masini E, Dolara P (2007) p-Coumaric acid, a common dietary phenol, inhibits platelet activity in vitro and in vivo. Br J Nutr 97(3):458-463. https://doi.org/10.1017/ S0007114507657882

33. Zou ZW, Xu LN, Tian JY (1993) Antithrombotic and antiplatelet effects of rosmarinic acid, a water-soluble component isolated from radix Salviae miltiorrhizae (danshen). Yao Xue Xue Bao 28(4):241-245

34. Chao PC, Hsu CC, Yin MC (2009) Anti-inflammatory and anti-coagulatory activities of caffeic acid and ellagic acid in cardiac tissue of diabetic mice. Nutr Metab (Lond) 6(1):33. https://doi.org/10.1186/1743-7075-6-33

\section{Publisher's Note}

Springer Nature remains neutral with regard to jurisdictional claims in published maps and institutional affiliations. 